\title{
Decreasing Microbial Fuel Cell Start-Up Time Using Multi- Walled Carbon Nanotubes
}

\author{
A. Jiménez-Rodríguez a ${ }^{\text {, A. Serrano }}{ }^{\text {b,c*, }}$, T. Benjumea ${ }^{\text {a,d }}$, R. Borja ${ }^{\text {b }}$, \\ M. El Kaoutit ${ }^{\mathrm{d}}$, F.G. Fermoso ${ }^{\text {b* }}$ \\ ${ }^{a}$ Departamento de Sistemas Físicos y Naturales, Universidad Pablo de Olavide, Ctra. de Utrera, km 1, 41013 Sevilla, Spain. \\ ${ }^{b}$ Instituto de la Grasa (C.S.I.C.), Ctra. de Utrera, km 1, 41013 Sevilla, Spain \\ ${ }^{c}$ School of Civil Engineering, The University of Queensland, Campus St Lucia, 4070, QLD, Australia.
}

${ }^{d}$ BioElectrochemistry for Lightweight and Integrated Analytical Solutions BioELIAS. S.L Spin-off of UPO Seville Ctra. Utrera, km 1 41013 Seville, Spain

\begin{abstract}
The bioelectrochemical systems are a sustainable technology that can be used to obtain electricity and/or reduced compounds. However, this novel technology presents several challenges prior to its implementation at full-scale. The aim of the present study was to evaluate different nanomaterials of electrode and mediators to increase the performance of BioElectrochemical Systems production. In order to achieve this objective, it was compared the use of Multiwall Carbon Nanotubes and Multiwall Carbon Nanotubes plus electron exogenous mediator (Meldola's Blue) against plain graphite anode in order to evaluate the overall start-up time and other electro-chemical features. The use of multiwalled carbon nanotubes reduces substantially (by 75\%) the start-up time required in a microbial fuel cell to produce stable voltage both, with and without the use of mediator compare to the plain anode. This reduction of the required time can be a consequence of the formation of anodic binders between this compound and the bacteria. With the independence of the start-up time, the current production was similar in the three studied cases, about $650 \mathrm{mV}$. Use of nanotubes modified anode surfaces might be especially interesting in cases of recovery after unstable operation of a microbial fuel cell, and/or reducing the start-up time for the generation of energy from new systems.
\end{abstract}

Keywords:

Microbial Fuel Cell;

Plain Graphite Anode;

Multiwall Carbon Nanotubes;

Electron Mediator.

\section{Article History:}

Received: 27 January 2019

Accepted: 02 April 2019

\section{1- Introduction}

The current global energy necessities are unsustainable in terms of environmentally, economically and socially. Globally, the energy supply is largely based on fossil fuels and nuclear power. All countries over the world recognize of vital importance to promote wide spread adoption of renewable energy to promote sustained economic growth, social development and environmental stewardship. Recently, BioElectrochemical Systems (BES) are an emerging ecofriendly technology for bioenergy generation in which, bacteria interact with substrate and exchange electrons, either directly or via redox mediators. The most studied BES is the microbial fuel cell (MFC), which converts the chemical energy of the organic compounds directly into electrical energy through the catalytic actions of anaerobic electrogenic microorganisms $[1,2]$.

The advantage of using MFC is that it possible to obtain electricity in circumstances where support electric is not possible. Although the power density of MFCs has increased more than 10,000 times in the past 10 years [3-5] the necessities of achieving increasing values is a challenge [6].

\footnotetext{
* CONTACT: A.serranomoral@uq.edu.au

DOI: http://dx.doi.org/10.28991/esj-2019-01174

(C) This is an open access article under the CC-BY license (https://creativecommons.org/licenses/by/4.0/).
} 
The mechanisms involved in electron transfer such as materials of electrode, mediators, electrolytes, and nature of the biocatalyst inoculum, are some of the process key and play a profound role in power generation. Hence, it is essential to select an appropriate material for electrode or to modify the anode surface with certain electroactive superficies that can facilitate electron transfer. Traditionally, carbon electrodes in the form of carbon paper or graphite rods tend to use it $[4,7]$. Graphite electrodes with roughened surface have shown to produce current density higher than smooth ones [8]. Likewise, increasing the surface area of materials has considerably increased current density [1, 8]. The use of nanotubes of carbon over graphite electrodes have received significant attention in fuel cell research for their unique structural and conductive properties, high surface area, high catalytic activity, and high resistance to corrosion [9].

Thus, Multiwall Carbon Nanotube (MWCNT) is a promising electrode material which might be used as an anode modifier in MFCs. Addition of MWCNT powder into the anode surface of a MFC is expected to give various desirable properties on the anode surface. Improvement of cell adhesion and growth is expected [10-12], and due to MWCNT unique electrical and structural properties catalyst support is expected as well [13].

There are some mechanisms implied in electron transfer. Several microbial species release electrons to the anode electrode directly, such as outer membrane proteins [14] others use their electroactive metabolites and self-produced electron shuttles such as flavins and phenazines [15].

Their own nanowires, outer membrane and periplasmic extensions are used to transport electron [16]. But, in their majority they do not readily release electrons without the intervention of some artificial/natural redox mediators [17]. Dye molecules and humic substances mediators such as methylene blue (MB), meldola's blue (MelB), thionine, naphthoquinone and neutral red; have been investigated on MFC performance [18].

The aim of the present study was to evaluate different nanomaterials of electrode and mediators to increase the performance of BES production. In order to achieve this objective, it was compared the use of MWCNT and MWCNT plus electron exogenous mediator (Meldola's Blue) against plain graphite anode in order to evaluate the overall start-up time and other electro-chemical features.

\section{2- Materials and Methods}

\section{2-1- MFC Designs}

The used MFC model is shown in the Figure 1. The MFC consists of two Plexiglas plates with a single flow channel, two electrodes, and two Plexiglas support plates. The two plates with a flow channel were separated by a cation exchange membrane (CMI-7000 CEM) with a total working volume of $33.6 \mathrm{ml}(11.2 \times 0.2 \times 1.5 \mathrm{~cm})(\mathrm{l} \times \mathrm{b} \times \mathrm{h})$. The other side of the flow channel faced the electrode. The anode and cathode were made of plain graphite (MR200, gas tight impregnated, from Müller \& Rössner GmbH \& Co., Troisdorf, Germany). The surface area of the flow channel, and thus the projected surface area of the electrodes in contact with solution, was $22 \mathrm{~cm}^{2}$.

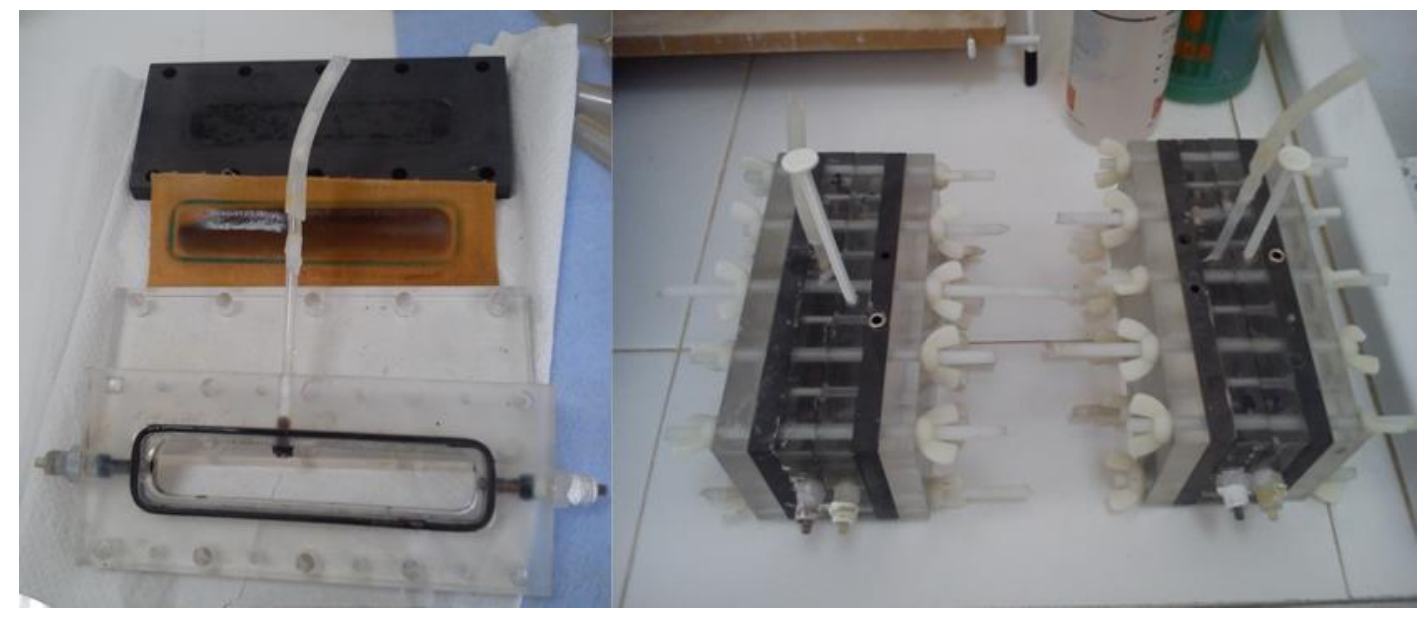

Figure 1. MFC picture. Grafite electrode (black); cation exchange membrane (yellow), and framework (transparent)

\section{1-1- Experimental Configuration}

Three MFCs with three different anode surface compositions were used. A first one with plain graphite anode surface. On a second one, MWCNT powder (773840 Sigma Aldrich) was applied on the anode surface. The MWCNT surface area was $280-350 \mathrm{~m}^{2} / \mathrm{g}$ ( $\geqslant 98 \%$ carbon basis). The third MFC anode surface was applied with MWCNT powder and mediators. The mediator consists in $10 \mathrm{mg}$ de Meldola's Blue (MB) (Alfa-Asier) and $20 \mathrm{ml}$ of DiMethylFormamide (DMF) (Sigma Aldrich). To study the anode performance, $\mathrm{Fe}(\mathrm{III})[\mathrm{CN}]_{6}{ }^{3-}$ was used as electron acceptor in the cathode. 
Acetate was fed as single substrate to the anode in all the cases. The followed research methodology is summarized in Figure 2.

$1^{\text {st }}$ Anodes preparation

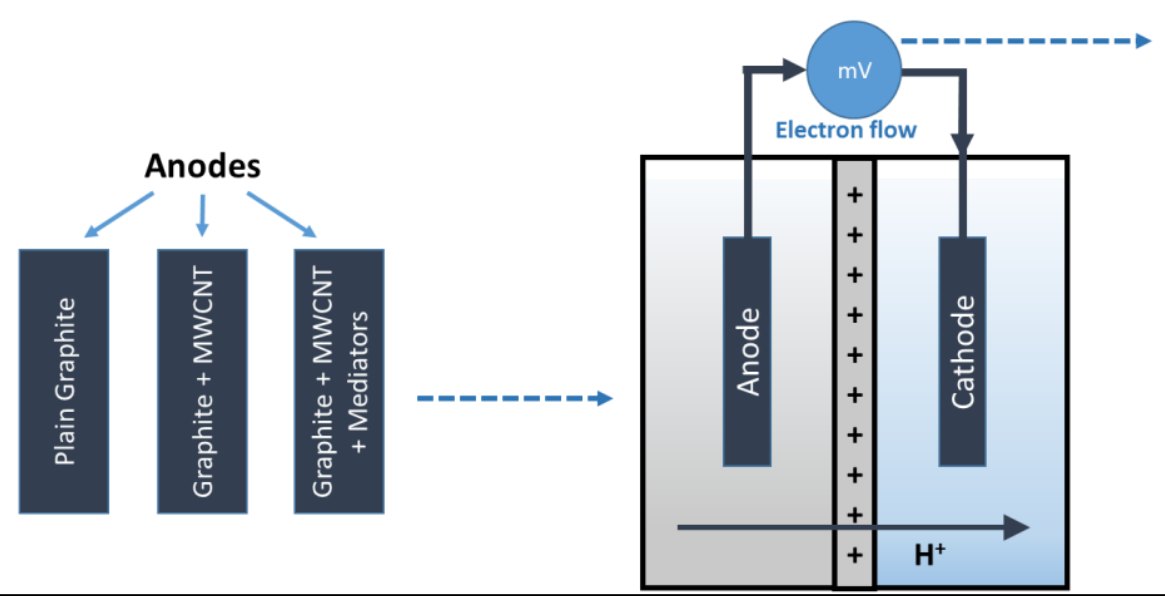

\section{$2^{\text {nd }}$ Comparison of the anodes for the start-up of MFCs}

\author{
Evaluation: \\ - Lag Phases duration \\ - Monitoring of the voltage \\ production \\ - Maximum voltage production
}

Figure 2. Schematic representation of the followed research methodology

\section{2-2- Anodes Preparation}

As first step, a cleaning process with alumina particles $(3 \mu \mathrm{m})$ was carried out for the preparation of all the used graphite anodes.

Subsequently, anodes with MWCNT and MWCNT+MB were sonicated during 20 min with nitric acid at 15\%, and then, they were sonicated during $15 \mathrm{~min}$ with acetone. After these steps, for MWCNT, the $100 \mathrm{mg}$ of material was dissolved with $5 \mathrm{ml}$ of DMF. For MWCNT+MB, $100 \mathrm{mg}$ of material was mixed with $10 \mathrm{mg}$ of MB and, then, they were dissolved with $5 \mathrm{ml}$ of DMF. Finally, they were uniformly distributed on the corresponded graphite anode surface.

Anaerobic microbial pellets were collected from a full-scale Upflow Anaerobic Sludge Blanket (UASB) reactor treating brewery wastewater. They were used as inoculum of all three MFCs. The main characteristics of this sludge were: $\mathrm{pH}$ : 7.5; Total Solids (TS): $69 \mathrm{~g} / \mathrm{L}$; and Volatile Solids (VS): $45 \mathrm{~g} / \mathrm{L}$.

\section{3- Results and Discussion}

Voltage profiles that occurred in the three MFCs with the different anode configurations are shown in Figure 3. As can be seen, the start-up time to reach stable maximum voltage was dramatically reduced when used MWCNT and MWCNT+MB compared to the plain graphite electrode. Concretely, around 40 days were needed to reach stable voltage production in plain graphite anode, while only around 10 days were needed to reach stable voltage production in both, MWCNT and MWCNT+MB. This represents a decrease of 75\% in the start-up time when these systems with multiwall carbon nanotubes are used compared to the plain graphite electrode. It was noticed that start-up time in the MWCNT+MB surface was even slightly (one day) shorter than the MWCNT surface, but it was not a significant difference. The reduction of the required start-up time was higher than that reported by Song et al. [19], which described a decrease of around $25 \%$. The reduction of the required time can be mainly explained by the increase of the available surface area in the anodes treated with MWCNT, which favour the formation of the biofilm [19, 20]. Moreover, other involved factor in the improvement on the performance of the MFC could be the improvement of the electron transfer rate, which is related with the adhesion of the microorganisms to the anode [21]. The adhesion is affected by the hydrophilic, electrostatic and van der Waals interactions between the anode surface and the microorganisms [19]. In fact, the preparation of the anodes MWCNT and MWCNT+MB with nitric acid carried out in the present study has been reported to increase the hydrophilic properties of the anodes because of the formation of functional groups [22]. The improvement derived of the addition of MB to the anode can be due to this compounds allows the formation of anodic binders between this compound and the bacteria. This phenomena was previously described by Li et al. [23], which reported that the effect derived of the addition of poly (bisphenol A-co-epichorohydrin) could be even more important that the hydrophily character of the anode.

Although start-up time of MFC required to approach stable voltage was substantially reduced. Maximum stable voltage has not shown a significant difference between the studied surfaces, i.e. around $+650 \mathrm{mV}$. This maximum stable voltage was close to the standard potential for the ferric/ferrous iron cathode, indicating that the microbial film in the MFCs were properly developed [24]. Moreover, these maximum stable voltages were similar than those obtained by Fermoso et al. [3], which reported a maximum voltage of $+680 \mathrm{mV}$ using a similar MFC and acetate as substrate. Song 
et al. [19] described that the surface modification of the anode with surfactant reduced the start-up time, although did not affected the reached stable voltage. Voltage profile is showing some dramatically decreasing production from time to time in the three studied cases (Figure 3). This behavior is due to substrate depletion. It is worth to notice how fast the current production is recovered after substrate addition.
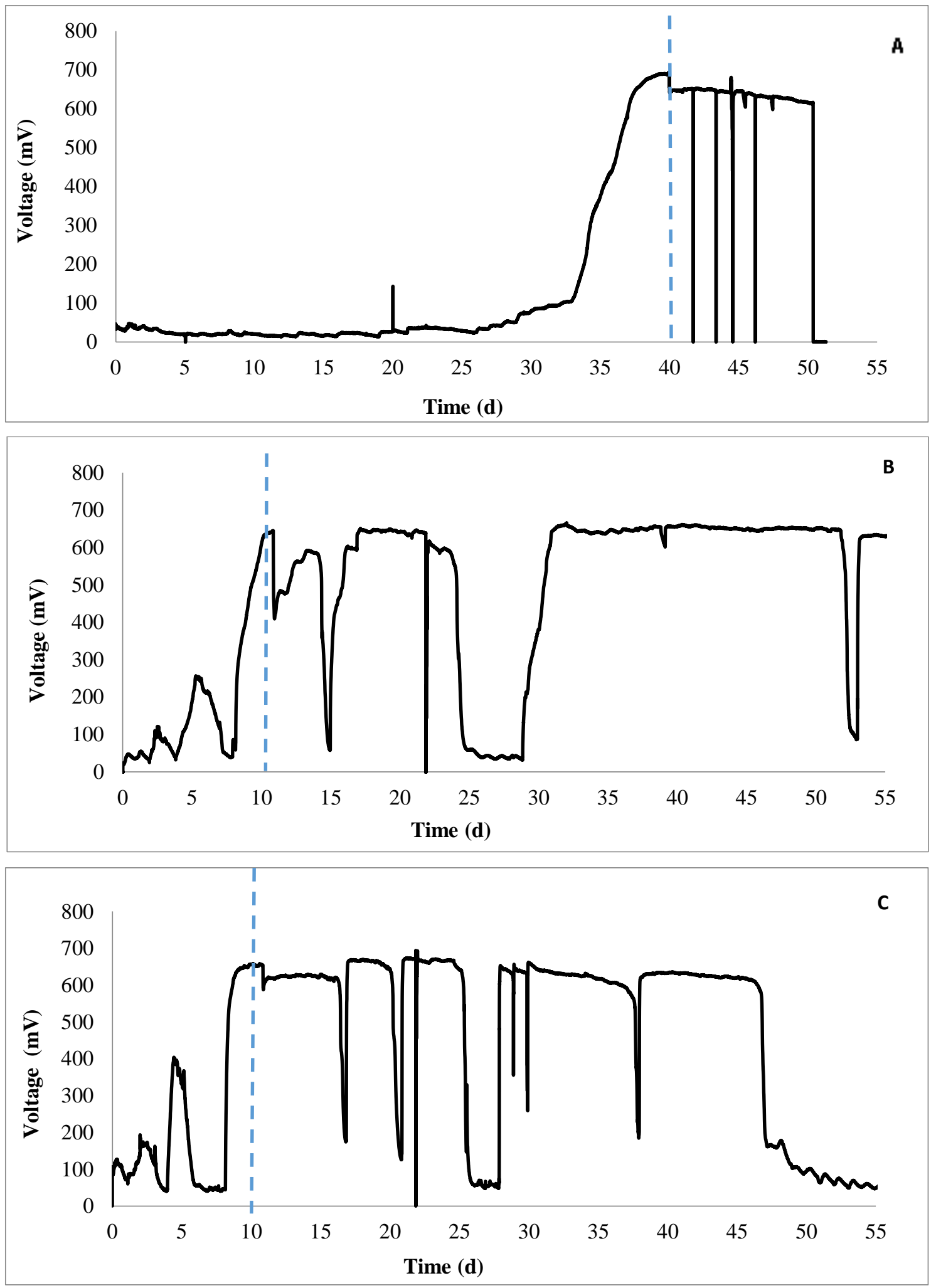

Figure 3. A. Voltage $(\mathrm{mV})$ versus time in an unmodified anode of the MFC; B. Voltage $(\mathrm{mV})$ versus time in a modified anode with multiwall nanotube (MWCNT); C. Voltage $(\mathrm{mV})$ versus time in a modified anode with multiwall nanotube and Meldola's Blue- Dimethylformamide (MWCNT+MB). 


\section{4- Conclusion}

The use of Multi-walled Carbon Nanotubes was very useful to decrease the required time for the start-up of a MFC. This improvement can be explained by the increase of the available surface area and/or an increase in the hydrophilic character of the anode. Likewise, short differences were obtained by the combination of MB to the nanotubes. This reduction of the required time can be a consequence of the formation of anodic binders between this compound and the bacteria. Further research is need to study if nanotubes application would be beneficial for long-term operation, especially in cases of recovery after unstable operation. Moreover, other mediators could be evaluated to maximize the biofilm formation rate and, hence, optimize the MFC behavior.

\section{5- Conflict of Interest}

The authors declare no conflict of interest.

\section{6- References}

[1] Rahimnejad, Mostafa, Ali Asghar Ghoreyshi, Ghasem Najafpour, and Tahereh Jafary. "Power Generation from Organic Substrate in Batch and Continuous Flow Microbial Fuel Cell Operations.” Applied Energy 88, no. 11 (November 2011): $3999-4004$. doi:10.1016/j.apenergy.2011.04.017.

[2] Liu, Xian-Wei, Xue-Fei Sun, Yu-Xi Huang, Guo-Ping Sheng, Shu-Guang Wang, and Han-Qing Yu. "Carbon Nanotube/chitosan Nanocomposite as a Biocompatible Biocathode Material to Enhance the Electricity Generation of a Microbial Fuel Cell." Energy \& Environmental Science 4, no. 4 (2011): 1422. doi:10.1039/c0ee00447b.

[3] Fermoso, F. G., M. J. Fernández-Rodríguez, A. Jiménez-Rodríguez, A. Serrano, and R. Borja. "Suitability of Olive Oil Washing Water as an Electron Donor in a Feed Batch Operating Bio-Electrochemical System." Grasas y Aceites 68, no. 2 (June 5, 2017): 198. doi:10.3989/gya.0216171.

[4] Logan, Bruce, Shaoan Cheng, Valerie Watson, and Garett Estadt. "Graphite Fiber Brush Anodes for Increased Power Production in Air-Cathode Microbial Fuel Cells.” Environmental Science \& Technology 41, no. 9 (May 2007): 3341-3346. doi:10.1021/es062644y.

[5] Rabaey, Korneel, and Willy Verstraete. "Microbial Fuel Cells: Novel Biotechnology for Energy Generation." Trends in Biotechnology 23, no. 6 (June 2005): 291-298. doi:10.1016/j.tibtech.2005.04.008.

[6] Ieropoulos, Ioannis, John Greenman, and Chris Melhuish. "Urine Utilisation by Microbial Fuel Cells; Energy Fuel for the Future." Phys. Chem. Chem. Phys. 14, no. 1 (2012): 94-98. doi:10.1039/c1cp23213d.

[7] Srikanth, S., T. Pavani, P.N. Sarma, and S. Venkata Mohan. "Synergistic Interaction of Biocatalyst with Bio-Anode as a Function of Electrode Materials." International Journal of Hydrogen Energy 36, no. 3 (February 2011): 2271-2280. doi:10.1016/j.ijhydene.2010.11.031.

[8] Sharma, Tushar, G. Suresh Kumar, and Jitendra S. Sangwai. "Enhanced Oil Recovery Using Oil-in-Water (o/w) Emulsion Stabilized by Nanoparticle, Surfactant and Polymer in the Presence of NaCl.” Geosystem Engineering 17, no. 3 (May 4, 2014): 195-205. doi:10.1080/12269328.2014.959622.

[9] Banks, C. E., and R. G. Compton. "New Electrodes for Old: From Carbon Nanotubes to Edge Plane Pyrolytic Graphite." Analyst 131, no. 1 (2006): 15-21. https://doi.org/10.1039/b512688f

[10] Sharma, T., A. L. Mohana Reddy, T. S. Chandra, and S. Ramaprabhu. "Development of Carbon Nanotubes and Nanofluids Based Microbial Fuel Cell." International Journal of Hydrogen Energy 33, no. 22 (2008): 6749-54. doi:10.1016/j.ijhydene.2008.05.112

[11] Correa-Duarte, M. A., N. Wagner, J. Rojas-Chapana, C. Morsczeck, M. Thie, and M. Giersig. "Fabrication and Biocompatibility of Carbon Nanotube-Based 3d Networks as Scaffolds for Cell Seeding and Growth." Nano Letters 4, no. 11 (2004): $2233-36$. doi:10.1021/n1048574f

[12] Liang, P., H. Wang, X. Xia, X. Huang, Y. Mo, X. Cao, and M. Fan. "Carbon Nanotube Powders as Electrode Modifier to Enhance the Activity of Anodic Biofilm in Microbial Fuel Cells." Biosensors and Bioelectronics 26, no. 6 (2011): 3000-04. doi: 10.1016/j.bios.2010.12.002

[13] Tsai, H. Y., C. C. Wu, C. Y. Lee, and E. P. Shih. "Microbial Fuel Cell Performance of Multiwall Carbon Nanotubes on Carbon Cloth as Electrodes." Journal of Power Sources 194, no. 1 (2009): 199-205. doi: 10.1016/j.jpowsour.2009.05.018

[14] Liu, H., R. Ramnarayanan, and B. E. Logan. "Production of Electricity during Wastewater Treatment Using a Single Chamber Microbial Fuel Cell." Environmental Science and Technology 38, no. 7 (2004): 2281-85. doi: 10.4314/ijest.v3i4.68540

[15] Ieropoulos, Ioannis A., John Greenman, Chris Melhuish, and John Hart. "Comparative Study of Three Types of Microbial Fuel 
Cell.” Enzyme and Microbial Technology 37, no. 2 (July 2005): 238-245. doi:10.1016/j.enzmictec.2005.03.006.

[16] Song, Y. C., D. S. Kim, J. H. Woo, B. Subha, S. H. Jang, and S. Sivakumar. "Effect of Surface Modification of Anode with Surfactant on the Performance of Microbial Fuel Cell." International Journal of Energy Research 39, no. 6 (2015): 860-68. doi: 10.1002/er.3284

[17] Kumar, G. G., V. G. S. Sarathi, and K. S. Nahm. "Recent Advances and Challenges in the Anode Architecture and Their Modifications for the Applications of Microbial Fuel Cells." Biosensors and Bioelectronics 43, no. 1 (2013): 461-75. doi: 10.1016/j.bios.2012.12.048

[18] Guo, K., S. Freguia, P. G. Dennis, X. Chen, B. C. Donose, J. Keller, J. J. Gooding, and K. Rabaey. "Effects of Surface Charge and Hydrophobicity on Anodic Biofilm Formation, Community Composition, and Current Generation in Bioelectrochemical Systems." Environmental Science and Technology 47, no. 13 (2013): 7563-70. doi: 10.1021/es400901u

[19] Zhu, Nengwu, Xi Chen, Ting Zhang, Pingxiao Wu, Ping Li, and Jinhua Wu. "Improved Performance of Membrane Free SingleChamber Air-Cathode Microbial Fuel Cells with Nitric Acid and Ethylenediamine Surface Modified Activated Carbon Fiber Felt Anodes.” Bioresource Technology 102, no. 1 (January 2011): 422-426. doi:10.1016/j.biortech.2010.06.046.

[20] Li, Hongying, Bo Liao, Juan Xiong, Xingwang Zhou, Huozhen Zhi, Xiang Liu, Xiaoping Li, and Weishan Li. "Power Output of Microbial Fuel Cell Emphasizing Interaction of Anodic Binder with Bacteria.” Journal of Power Sources 379 (March 2018): 115-122. doi:10.1016/j.jpowsour.2018.01.040.

[21] Uría, Naroa, David Sánchez, Roser Mas, Olga Sánchez, Francesc Xavier Muñoz, and Jordi Mas. "Effect of the Cathode/anode Ratio and the Choice of Cathode Catalyst on the Performance of Microbial Fuel Cell Transducers for the Determination of Microbial Activity.” Sensors and Actuators B: Chemical 170 (July 2012): 88-94. doi:10.1016/j.snb.2011.02.030. 